\title{
Test Study on Composite Strengthened Beam with CFRP Board, Angle Steel and External Prestressed Steel Strand
}

\author{
Tao Jiang ${ }^{1, *}$, BiQing $\mathrm{Li}^{1}$ and kai Chen ${ }^{2}$ \\ 1. Jiangsu Southeas Special Technical Engineering Co., Ltd, Nanjing, 210008, China \\ 2. School of Civil Engineering, Southeast University, Jiangsu Nanjing, 210096, China
}

\begin{abstract}
The composite strengthening beam combined with a variety of reinforcement technology, complementary advantages.In order to study the mechanical behavior of T-beam strengthened with CFRP board, external angle steel and external prestressed steel strand, six reinforced test beams were fabricated to compare and analyze the structural characteristics of bending stiffness, crack development and bearing capacity. The research shows that the beam strengthened by CFRP board, external angle steel and external prestressed steel strand has good working performance. The rebound force of the bending deformation of the external angle steel and the upward force of the external prestressed steel strand reliably anchor the carbon fiber board, avoiding the bond failure and slippage of the CFRP.The three kinds of reinforcing materials work together and complement each other, which can give full play to their respective strength. The composite strengthened beam with CFRP board, external angle steel and external prestressed steel strand can greatly improve the cracking load, structural stiffness and ultimate bearing capacity of the original beam, and the reinforcement effect is optima.
\end{abstract}

\section{Introduction}

A single reinforcement method has its own advantages and disadvantages, and it is often unable to complete the reinforcement beam with a large bearing capacity demand. Therefore, it is necessary to consider using multiple reinforcement methods to comprehensively strengthen the structural beam at the same time, so as to form a comprehensive reinforcement beam. Comprehensive reinforcement beams complement each other's advantages and work together to give full play to the performance of various reinforcement materials ${ }^{[1-3]}$.

Sticking carbon fiber board, outsourcing Angle steel and external prestressing are the most commonly used reinforcement methods for reinforced concrete beams. There are many successful reinforcement projects. The three reinforcement methods have their own advantages and disadvantages. When a large strengthening bearing capacity is needed, if carbon fiber plate is used for reinforcement, interface peeling failure and anchoring failure will occur due to insufficient bond strength between carbon fiber plate and concrete, so the strength of carbon fiber material cannot be fully utilized ${ }^{[4-7]}$. If the outsourcing Angle steel reinforcement with larger geometry size is adopted, the construction is difficult and the cost of reinforcement is high. If a large number of external prestressing tendons are used for reinforcement, there will be adverse phenomena such as overarching and upper flange being pulled apart. Therefore, if the three reinforcement methods of sticking carbon fiber plate, outsourcing Angle steel and external prestress are applied comprehensively, the composite reinforcement beam of sticking carbon fiber plate-outsourcing Angle steel and external prestress can be formed, so as to achieve the optimal comprehensive effect of strengthening beam ${ }^{[8-10]}$..

Pasting carbon fiber board - outsourcing Angle externally prestressed composite beam is the use of Angle steel bending deformation of rebound and prestressed reinforcement method is lifted up to reliable anchorage of the carbon fiber plate, can reduce the carbon fiber board bond-slip, ensure that the carbon fiber plate material strength, give full play to the three kinds of reinforcement materials to work together, the comprehensive reinforcement beam can greatly improve the cracking load and ultimate load, significantly improve the performance of the concrete beam.

\section{Design of reinforced beam}

Six reinforced beams were made, and comparative experiments were carried out to analyze and study the bearing capacity, deformation capacity and fracture development of the beams with CFRP - Angle steel external prestressed steel strand composite reinforcement. Reinforcement method and beam number of test beam are shown in Table 1.

\footnotetext{
* Corresponding author: Tao Jiang, 13815419890@163.com
} 
Table1. Test beam number and reinforcement method

\begin{tabular}{c|c}
\hline $\begin{array}{c}\text { Test } \\
\text { beam no. }\end{array}$ & Reinforcement description of beams \\
\hline L1 & Unreinforced (original beam) \\
\hline L2 & Paste carbon fiber sheet reinforcement \\
\hline L3 & External Angle reinforcement \\
\hline L4 & $\begin{array}{c}\text { Paste carbon fiber board - external Angle steel } \\
\text { reinforcement }\end{array}$ \\
\hline L5 & External prestressed reinforcement \\
\hline L6 & $\begin{array}{c}\text { Carbon fiber plate - external Angle steel - } \\
\text { external pre - stress reinforcement }\end{array}$ \\
\hline
\end{tabular}

\section{(1) Test the original beam $L 1$}

Test the original beam of reinforced concrete simply supported $\mathrm{T}$ beam (as shown in figure 1), test beam total length of $6000 \mathrm{~mm}$, calculation of span is $5700 \mathrm{~mm}$, high beam of $500 \mathrm{~mm}$, the bottom of the beam width of 200 $\mathrm{mm}, \mathrm{HRB} 400$ reinforced by using the bottom longitudinal steel beams, with two phi 16 steel bar, steel section reinforcement ratio of $0.335 \%$, reinforced HPB 235 level by using the longitudinal compression steel roof beams, with 4 phi 10 steel bar, stirrup used reinforced HPB235 level, stirrup for phi $8 @ 150$, the strength grade of concrete design for $\mathrm{C} 25$.
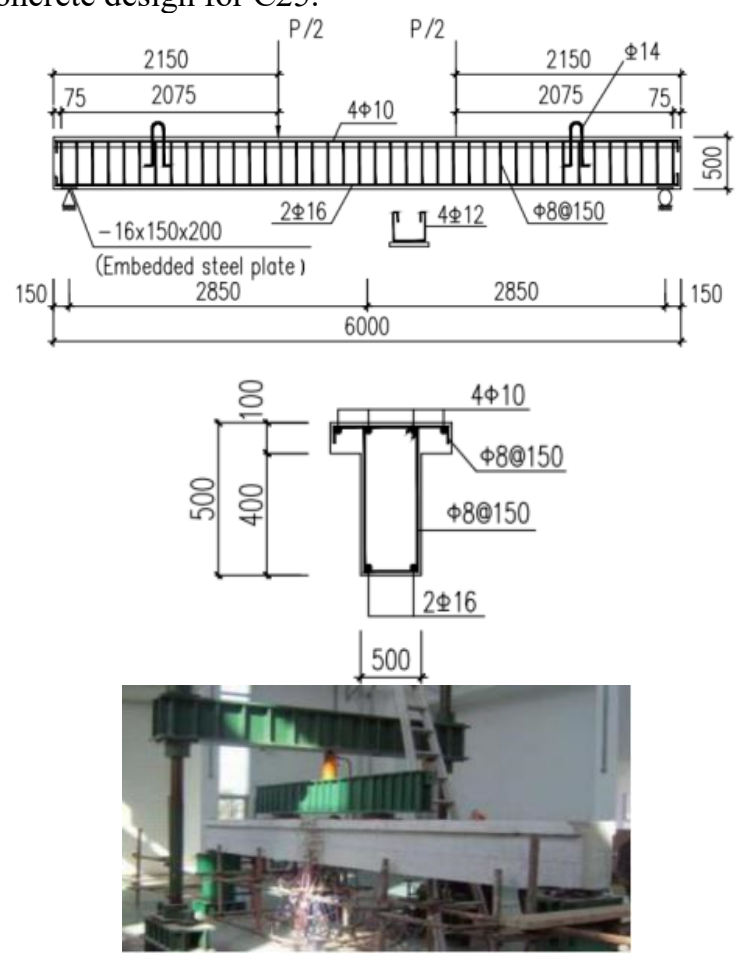

Figure 1. Schematic diagram of original beam reinforcement and test site diagram

(2) beams strengthened with carbon fiber plates $\mathbf{L 2}$

A $1.4 \mathrm{~mm}$ thick $200 \mathrm{~mm}$ wide $6 \mathrm{~m}$ overlaid carbon fiber plate is pasted at the bottom of L2 beam. The carbon fiber boardf $_{\text {ptk }}=3000 \mathrm{MPa}$. The carbon fiber plate is provided with special clamping steel plate with tooth groove at the end of the beam to anchor the carbon fiber plate. Three $100 \mathrm{mmU}$ type steel rings are set at both ends, and four $100 \mathrm{~mm}$ wide U-type steel rings are pasted in the middle.Fig. 2 shows the test site of L2, a beam strengthened with carbon fiber plates.

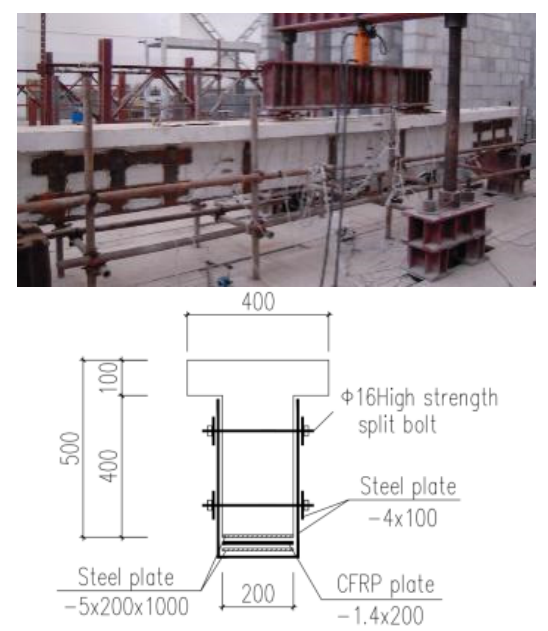

Figure 2. Test site diagram of reinforced beam L2

(3) Reinforced beam L3 with external Angle steel

Both sides of the bottom of L3 beam are supported by Angle steel. Angle steel of Model L50 $\times 50 \times 5$ is made of Q235B, which is symmetrically bonded to both sides of the beam bottom and anchored with steel hoop plate.

The two ends of the beam are anchored by two Ushaped steel hoop with a spacing of $250 \mathrm{~mm}$ and a width of $80 \mathrm{~mm}$. In the beam, four steel hoop plates with a width of $80 \mathrm{~mm}$ are set in corresponding positions.

The test site of L3 reinforced beam with outsourcing Angle steel is shown in Figure 3.

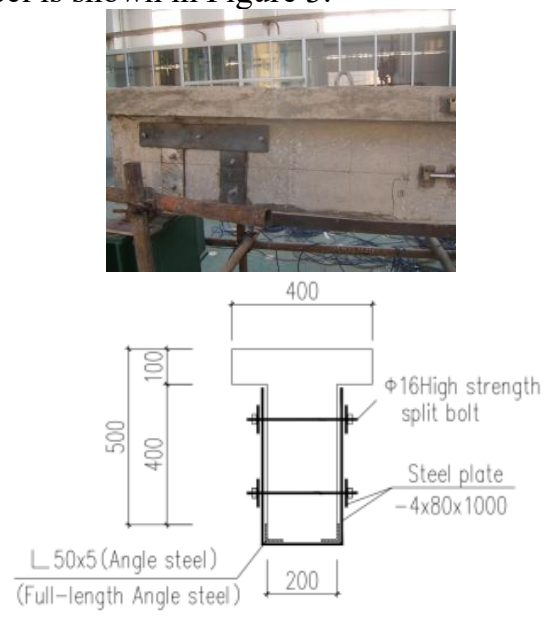

Figure 3. Test site diagram of reinforced beam L3

\section{steel}

(4)CFRP - reinforced beam L4 with external Angle

This beam is a composite reinforcement beam with carbon fiber bonded to external Angle steel. The Angle steel normal force is used to anchor the carbon fiber plate reliably and work together. Paste carbon fiber plate according to the production method of L3, paste steel pressure plate with thickness of $5 \mathrm{~mm}$, length of $170 \mathrm{~mm}$ and width of $50 \mathrm{~mm}$ at every interval of $250 \mathrm{~mm}$ under the carbon fiber plate, then paste Angle steel on both sides of the bottom of the beam for support, and finally set up three U-shaped steel band plates at the end of the beam, and set up four U-shaped steel band plates at the middle of the beam. FIG. 4 shows the test site of the composite reinforcement beam L4 with carbon fiber plate-outsourcing Angle steel. 


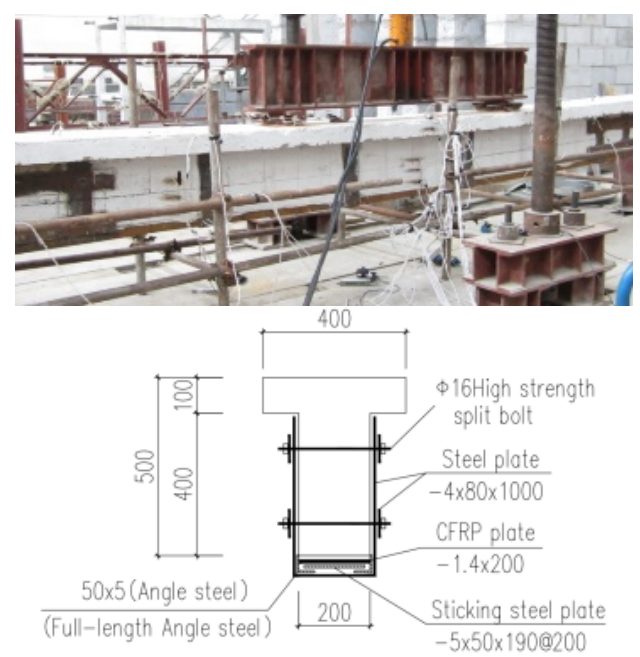

Figure 4. Test site diagram of reinforced beam L4

\section{(5) Externally prestressed reinforced beam L5}

The external prestressed reinforcement beam L5 is the external prestressed reinforcement beam. The external prestressed reinforcement bars are $2 \varphi^{2} 15.2$ unbonded tendons and the external prestressed steel strand is in the form of double broken lines. The prestressing tendons are arranged symmetrically, the area of each beam section $A_{p}=139 \mathrm{~mm}^{2}$, the standard value of tensile strength $\mathrm{f}_{\mathrm{ptk}}=1860 \mathrm{MPa}$, and the tension control stress are $: \sigma_{\text {con }}=1023 \mathrm{MPa}$. The effective stress readings of the prestressing tendons obtained by the pressure sensors on both sides are approximately the same, and the actual effective prestress is about 900MPa. The test site of externally prestressed reinforced beam L5 is shown in Figure 5.

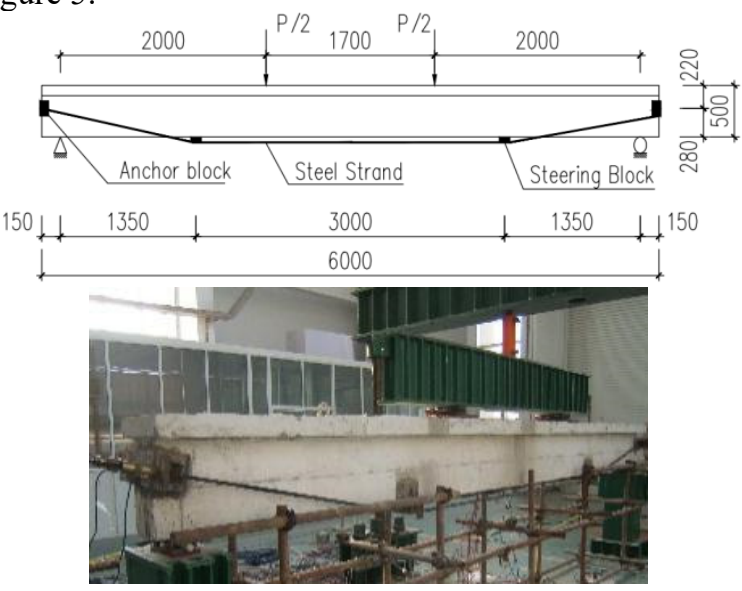

Figure 5. Test site diagram of reinforced beam L5

(6) Carbon fiber plate - external Angle steel external prestressed reinforcement beam $\mathrm{L} 6$

The reinforcement beam L6 is made according to the method of L4 (carbon fiber plate-angle steel composite reinforcement beam), and then the external prestressing is applied according to the construction process of L5 (external prestressing reinforcement beam). By using Angle steel rebound force and normal force of prestressing steel to anchor carbon fiber plate reliably, the bonding slip of carbon fiber plate can be reduced and the strength of carbon fiber plate can be fully exerted. The three reinforcement materials work together and complement each other. FIG. 6 shows the test site of externally prestressed reinforced beam L6 with CFRP plates and Angle steel.

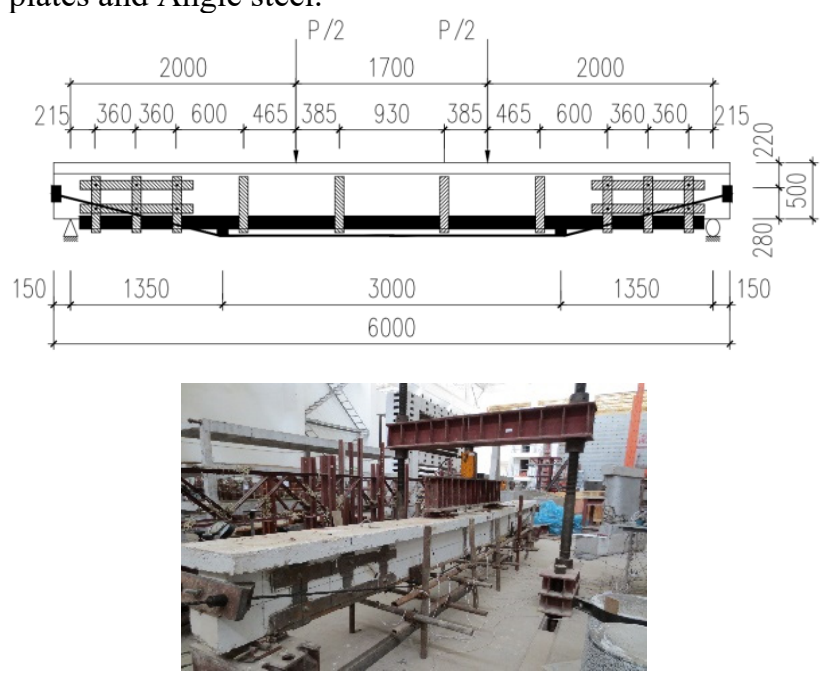

Figure 6. Test site diagram of reinforced beam L6

\section{The test phenomenon}

\section{(1) Unreinforced beam (L1)}

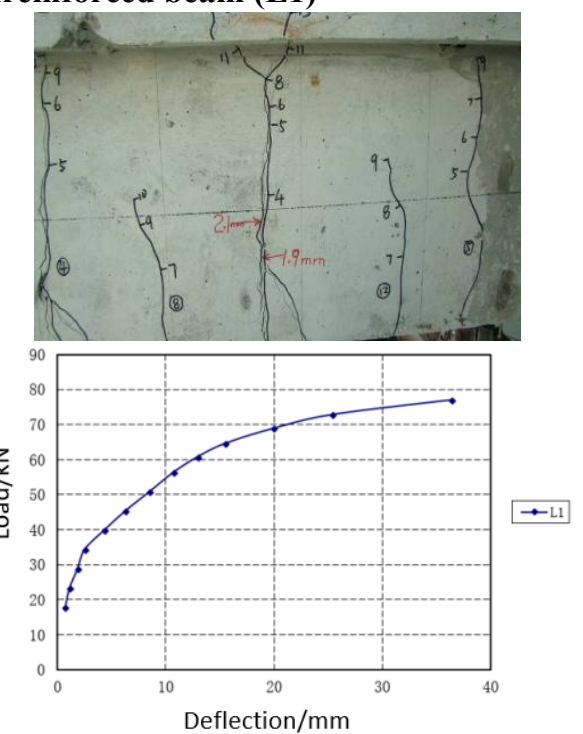

Figure 7. Load - deflection curve of L1 midspan

When the load was applied to $34.33 \mathrm{kN}$, the first subtle vertical vertical crack was observed near the mid-span of the test beam, and the measured vertical deflection of the mid-span of the beam was $2.51 \mathrm{~mm}$. With the increase of the load, new cracks appear in the section near the loading point and the pure bending section of the middle span. The original cracks extend upward on the basis of the original cracks, the crack width increases, and the deflection of the beam increases faster than that before the cracking. When loading to $56.32 \mathrm{kN}$, cracks occur at $1 / 4$ span away from the support, and the longest crack in the middle span has developed to the bottom of the flange of the T-beam. When the load is increased to $68.86 \mathrm{kN}$, the tensile reinforcement in the beam yields, the deflection of the beam increases sharply, the cracks in the pure bending section of the span 
are uniformly distributed, and most of the cracks converge at the bottom of the beam. When the load increases to $77.15 \mathrm{kN}$, the reinforcement strain increases sharply, the crack width expands rapidly, and the deflection development speeds up. Finally, the maximum crack width of the beam reaches $2.1 \mathrm{~mm}$, the measured deflection value is $36.43 \mathrm{~mm}$, and the loading is terminated.

(2) Bonded carbon fiber reinforced beam (L2)

When the load was added to $36.09 \mathrm{kN}$, the first crack appeared. After the crack appeared, the strain of the carbon fiber plate suddenly increased. As the load increases, bending cracks develop rapidly and longitudinal cracks appear on the carbon fiber plates. When the load reaches $118.11 \mathrm{kN}$, the tensile reinforcement reaches its yield, and the "crackle" sound is obviously heard at this time, and the carbon fiber plate slides locally. The load continues to increase, and when it reaches $145.61 \mathrm{kN}$, the crack width reaches $2.0 \mathrm{~mm}$, which is judged to be the ultimate state of the beam. The crack load of the carbon fiber reinforced beam L2 is slightly increased, and with the development of cracks, the bonding and sliding phenomenon occurs, and finally the arch tie system is formed (the anchor-fixture is reliable). After cracking, the crack develops rapidly and the cracking load decreases rapidly, and the beam stiffness decreases rapidly, and the ultimate bearing capacity is improved compared with the original beam L1.
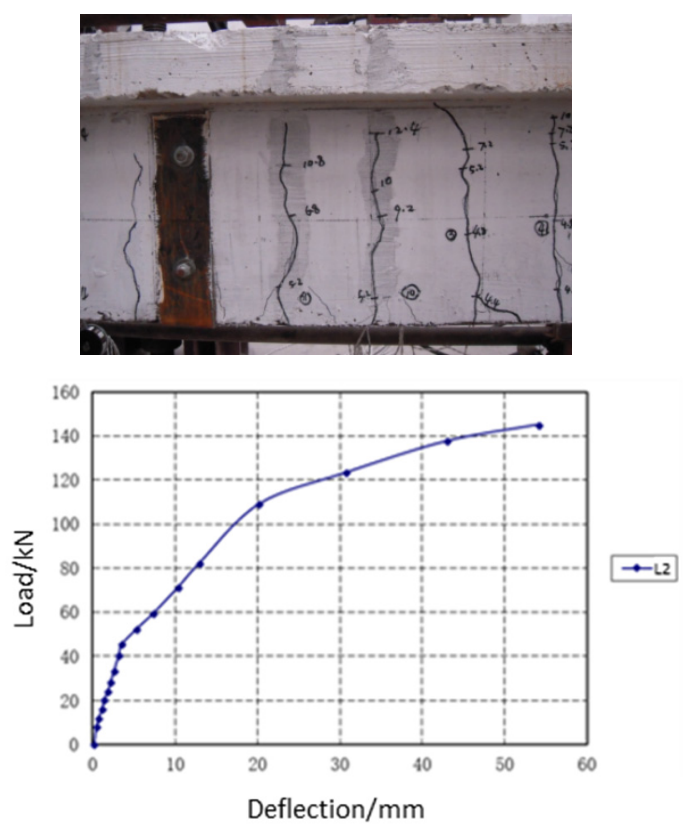

Figure 8. L2 shows the load-deflection curve of the mid-span

\section{(3) External Angle reinforced beam (L3)}

At the beginning, the load-deflection curve of the beam was basically linear. When the beam was loaded to $35 \mathrm{kN}$, cracks began to appear in the beam body, with fewer and thinner cracks, the width of which was $0.02 \mathrm{~mm}$ and the deflection was $2.26 \mathrm{~mm}$. When loading continued, the deflection increased, but the load-deflection curve remained uniform, and the cracks were still relatively small. When loading reached $172.2 \mathrm{kN}$, the Angle steel began to yield, and the cracks suddenly increased to $0.72 \mathrm{~mm}$, with more cracks appearing, and the mid-span deflection was $20.2 \mathrm{~mm}$. When loading to $217.1 \mathrm{kN}$, the crack width has reached $2.0 \mathrm{~mm}$, the deflection has increased to $43.24 \mathrm{~mm}$, and the test is terminated. The test shows that the outsourced Angle steel reinforced beam L3 has good working performance.
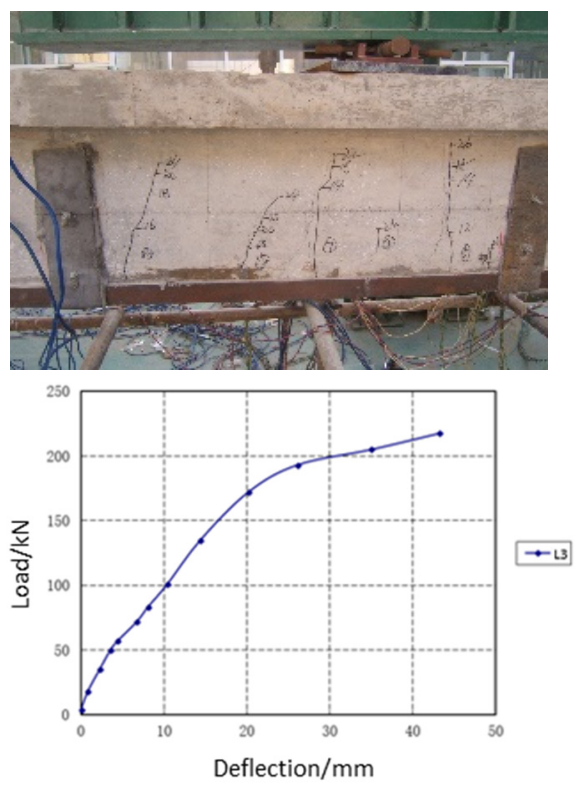

Figure 9. L3 Load - deflection curve of mid-span

(4) CFRP reinforced beam with external Angle steel (L4)

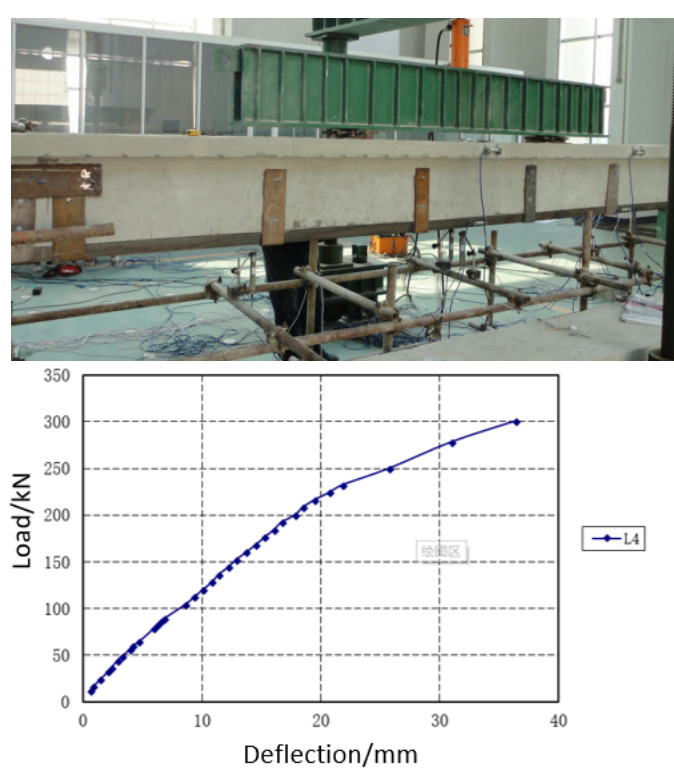

Figure 10. L4 Mid-span load - deflection curve

At the beginning of loading, the deflection of the beam changes uniformly with the increase of load. When the beam is loaded to $47.67 \mathrm{kN}$, the first crack begins to appear, and the deflection of the beam is $3.25 \mathrm{~mm}$. When the loading continues, the increment of deflection increases, but the load-deflection curve still changes uniformly, and the cracks are still fine. When the load is added to $231.67 \mathrm{kN}$, the Angle steel begins to yield, and the cracks suddenly increase to $1.36 \mathrm{~mm}$, resulting in bending, shear and oblique cracks, and the deflection of the beam body is 
$31 \mathrm{~mm}$. When loading continues to $298.42 \mathrm{kN}$, the crack width has reached $1.8 \mathrm{~mm}$, and the deflection has reached $36.4 \mathrm{~mm}$. After stopping loading, the crack is basically closed after unloading. Test beam stiffness L4 stiffness degradation is not obvious in the whole failure process, crack development overall small and concentrated, as a result of the existence of Angle steel, Angle steel rebound method to force to reliable anchorage of the carbon fiber plate, can reduce the carbon fiber plate bond-slip, ensure that the carbon fiber plate material strength, give full play to the two types of reinforcement materials to work together, the complementary advantages. The carbon fiber board bonded well to the beam body, and there was no obvious bond slip.

(5) Externally prestressed reinforced beam (L5)

At the initial stage of loading, $20 \mathrm{kN}$ is applied step by step, and the deflection, stress of non-prestressed reinforcement and stress of steel strand of the beam body increase slowly, which is basically linearly related to the load growth. When the load increased to $100 \mathrm{kN}, 10 \mathrm{kN}$ was loaded step by step until $118.1 \mathrm{kN}$, vertical cracks appeared near the loading point, and the deflection value in the span was $6.54 \mathrm{~mm}$. When the load increased to $163.1 \mathrm{kN}$, the ordinary steel bars began to yield, the deflection of the beam increased rapidly, new vertical cracks appeared in the pure bending section of the span, and the original cracks began to extend up and down.

When the load increases to $190.1 \mathrm{kN}$, the crack extends up to the lower edge of the wing plate, the maximum crack width has reached $1.5 \mathrm{~mm}$, the mid-span deflection value is $23.46 \mathrm{~mm}$, and the loading stops.
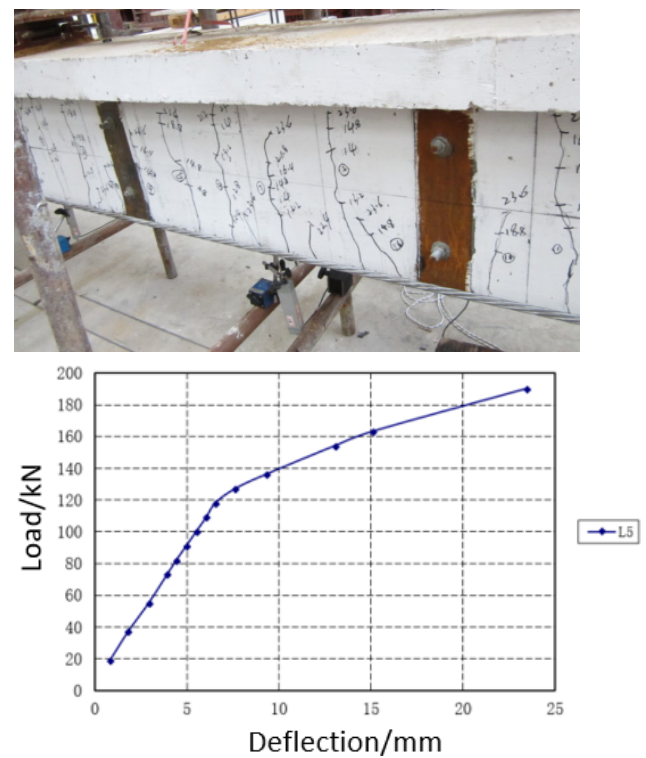

Figure 11. L5 Mid-span load - deflection curve

(6) Carbon fiber plate - external Angle steel External prestressed reinforcement beam (L6)

Began to load the girder deflection of uniform change appears as load increases, the load of $181.30 \mathrm{kN}$ beam body began to appear when the first crack, deflection of beam body is $8.92 \mathrm{~mm}$, load - deflection curve of a turning point, with the load increasing, pure bending section and cross section near mount point across in the emergence of new cracks, the original cracks on the basis of the extended upward, crack width increase; When loaded to $252.13 \mathrm{kN}$, bending, shear and oblique cracks began to appear in the beam body. When the load is applied to $341.60 \mathrm{kN}$, the cracks are basically complete and the maximum crack width is $0.3 \mathrm{~mm}$. When loading to $379.32 \mathrm{kN}$, the reinforcement yielded and the loaddeflection curve began to show turning points. When loading continues to $455.56 \mathrm{kN}$, the crack width reaches $1.6 \mathrm{~mm}$, and the test stops. By using Angle steel rebound force and normal force of prestressing steel to anchor carbon fiber plate reliably, the bonding slip of carbon fiber plate can be reduced and the strength of carbon fiber plate can be fully exerted. The three reinforcement materials work together and complement each other.
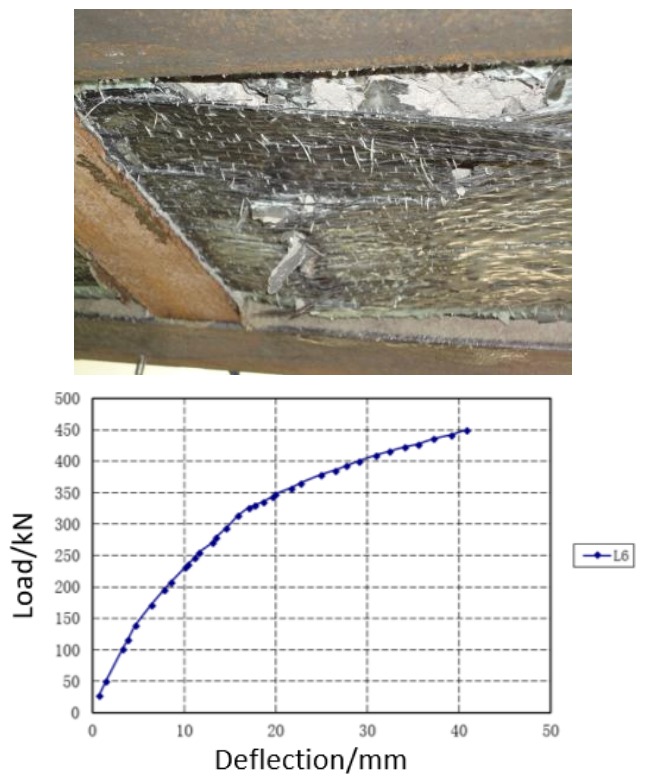

Figure 12. L6 Mid-span load - deflection curve

\section{Comparative analysis of test results}

The cracking load, yield load and ultimate load of the test beam obtained by load test are summarized in Table 2 .

Table2. L1 L6 Summary table of test result data

\begin{tabular}{c|c|c|c}
\hline \multirow{2}{*}{ Beam no. } & \multicolumn{3}{|c}{$P(\mathrm{kN})$} \\
\cline { 2 - 4 } & $P_{\mathrm{cr}}$ & $P_{\mathrm{y}}$ & $P_{\mathrm{u}}$ \\
\hline L1 & 34.33 & 68.86 & 77.15 \\
\hline L2 & 36.09 & 118.11 & 145.61 \\
\hline L3 & 35.00 & 193.10 & 217.10 \\
\hline L4 & 47.67 & 230.39 & 298.42 \\
\hline L5 & 118.14 & 163.10 & 190.22 \\
\hline L6 & 127.26 & 379.32 & 455.56 \\
\hline
\end{tabular}

\subsection{Ultimate load}

The analysis shows that the three strengthening methods, including sticking carbon fiber plate, outsourcing Angle steel and external prestressing, can effectively increase the ultimate load of the original beam. The comprehensive strengthening beam has complementary advantages in 
collaborative work, and the comprehensive strengthening beam can greatly increase the ultimate load of the original beam. The column diagram of ultimate load of the strengthened test beam is shown in Figure 14.

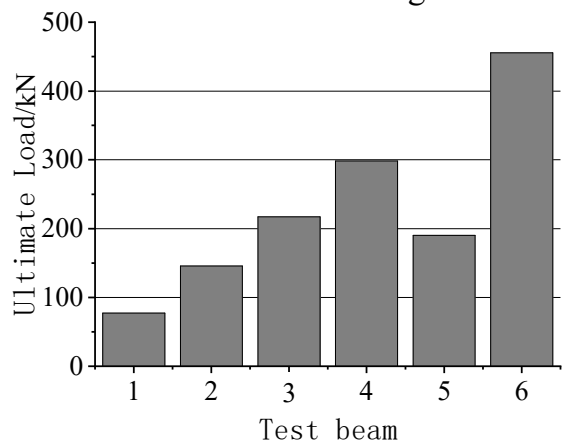

Figure 13. Column diagram of ultimate load of test beam

L2 (CFRP reinforced beam) is increased by $(68.46 \mathrm{kN})$ 88.7\%. CFRP strengthened with CFRP has little effect on the ultimate bearing capacity of concrete beam, because CFRP sheets fail to give full play to the material strength due to the bonding slip of CFRP sheets in the mid-span area of beam in the test. Although the anchoring fixture was firm, the arching rod system was formed in the later stage of the test beam, resulting in the rapid development of cracks in the test beam, which reached $2.0 \mathrm{~mm}$ and the test was terminated.

The ultimate loads of L3 (outfitted Angle reinforced beam) and L5 (externally prestressed reinforced beam) were increased by $(139.95 \mathrm{kN}) 181.4 \%$ and $(113.07 \mathrm{kN})$ $146.6 \%$, respectively, compared with the original L1 $(77.15 \mathrm{kN})$. Therefore, the two reinforcement methods (external Angle steel reinforcement and external prestress reinforcement) have a better effect on increasing the ultimate bearing capacity of concrete beams.

L4 (pasting carbon fiber plate - outsourcing Angle steel reinforcement beam) composite reinforcement beam the limit load of $221.27 \mathrm{kN}$ (286.8\%) increased, respectively, compared with the $\mathrm{L} 1$, and separately use pasting carbon fiber board reinforcement beam L2, paste the Angle steel reinforcement beam L3 limit load by 68.46 $\mathrm{kN}(88.7 \%), 139.95 \mathrm{kN}(181.4 \%)$, and the improvement of L4 limit load capacity than the L2, L3 the improvement of the larger sum, namely the "1 $+1>2$ "reinforcement effect.

L6 (Carbon fiber plate - external Angle steel - external prestressed reinforcement beam) composite beam reinforcement of ultimate load increased $378.41 \mathrm{kN}$ (490.5\%), and single beam strengthened with pasting carbon fiber plate L2, paste the Angle steel reinforcement beam L3 and L5 externally prestressed reinforcement beam limit load $68.46 \mathrm{kN}$ increased respectively $(88.7 \%)$, $139.95 \mathrm{kN}(181.4 \%)$, and $113.07 \mathrm{kN}(146.6 \%)$, increase the amount of L6 limit load than L2, L3 and L5 both increase the sum of the amount, which produced the "1+ $1+1>3$ "reinforcement effect.

From the test results of the above six reinforced beams, the reinforcement effect of L4 and L6 is the most obvious, which fully demonstrates the superiority of the comprehensive reinforcement in improving the ultimate bearing capacity.

\subsection{Correlation curve of load and displacement}

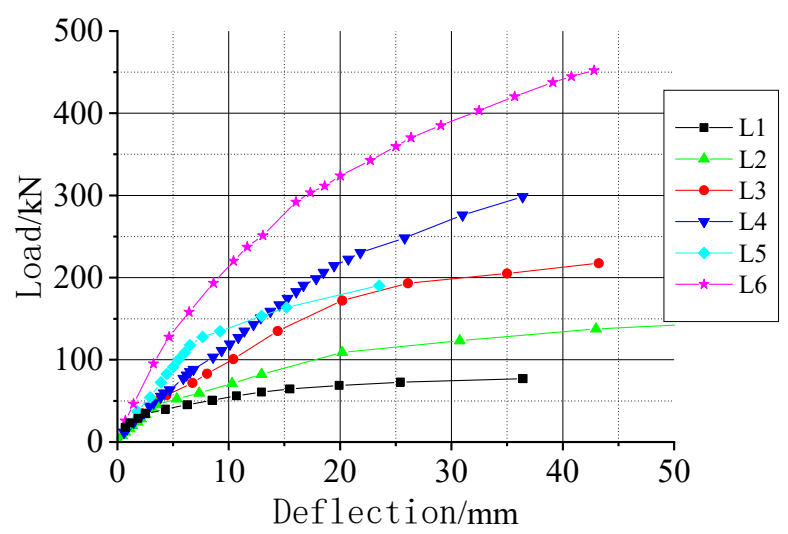

Figure 14. The correlation curve between load and displacement in mid-span position

As can be seen from Figure 15 the stiffness of the original beam L1 decreases rapidly after cracking, and the ultimate bearing capacity is very low. The cracking load of the strengthened beam L2 with carbon fiber plate is slightly increased, but with the development of cracks, the phenomenon of bonding and slippage occurs, and eventually the arching rod system is formed (the anchorclamp is reliable), resulting in the rapid decrease of the stiffness of the strengthened beam L2 and a slight increase in the ultimate bearing capacity compared with the original beam L1. The cracking load of Angle steel strengthened beam L3 is increased to some extent, and the ultimate bearing capacity is increased to some extent compared with the original beam L1 as the stiffness of crack development decreases slowly, which indicates that Angle steel strengthened beam L3 has good working performance. The cracking load of beam L4 reinforced with carbon fiber plate-outsourcing Angle steel is greatly increased, and the ultimate bearing capacity is greatly increased compared with the original beam L1 as the stiffness decreases slowly with the development of cracks, indicating that beam L4 reinforced with carbon fiber plate-outsourcing Angle steel has good working performance, and the two reinforcement materials have complementary advantages in cooperative work. The cracking load of externally prestressed reinforced beam L5 is greatly increased. After the cracking of beam body, the crack develops rapidly. With the rapid decline in the stiffness of crack development, the ultimate bearing capacity is improved compared with the original beam L1. Stick carbon fiber plate Angle -- - outsourcing externally prestressed reinforcement beam L6, cracking load is greatly improved, with the development of fracture stiffness fell very slowly, ultimate bearing capacity than the original beam L1 greatly improved, show that the carbon fiber plate - outsourcing Angle - in vitro prestressed composite beam L6 has good work performance, work with three kinds of reinforced materials have complementary advantages, the reinforcement effect optimal. 


\subsection{Correlation curve of load and crack width}
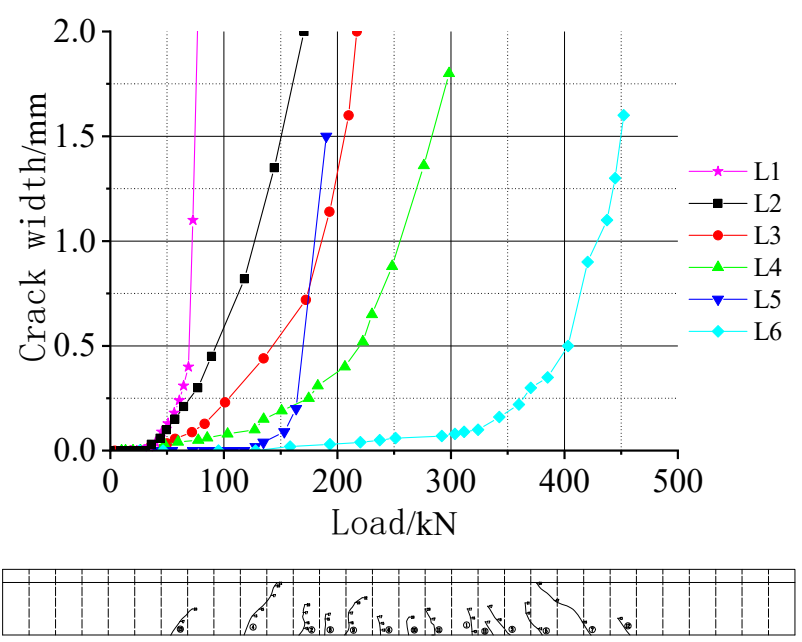

Figure 15. The correlation curve between load and crack width in mid-span position

It can be seen from the development curve of crack width of the six reinforced beams that the crack load of original Beam L1 is low, the crack spacing after cracking is large, and the crack development is very rapid. The cracking load of L2 beam strengthened by carbon fiber plate is slightly increased, but with the development of cracks, the phenomenon of bonding and slippage occurs, and eventually the arching rod system is formed (the anchoring fixture is reliable). After cracking, the crack spacing decreases to some extent and the crack develops rapidly. The crack load is increased, the crack spacing is small, and the crack development is slow. With the slow development of cracks, the crack spacing is relatively dense, which indicates that the CFRP composite reinforced beam L4 has good working performance, and the two reinforcement materials have complementary advantages in cooperative work. The crack load of externally prestressed reinforced beam L5 is greatly increased, and the crack spacing is large and develops rapidly after the crack of the beam body. Carbon fiber board - outsourcing Angle - externally prestressed composite beam L6, has greatly improve the cracking load, crack spacing is very dense, crack development is very slow, show that the carbon fiber plate - outsourcing Angle - externally prestressed composite beam L6 has good work performance, work with three kinds of reinforced materials have complementary advantages, the reinforcement effect optimal.

\section{5 conclusions}

1) The carbon fiber plate-external Angle steel-external prestressed composite reinforcement beam has good mechanical performance. The three reinforcement materials work together to enhance strengths and avoid weaknesses, complement each other's advantages and achieve the best reinforcement effect.

2) The reflexion of the bending deformation of the external Angle steel and the upward lifting force of the prestressed reinforcement method reliably anchor the carbon fiber plate, avoid the bonding and sliding phenomenon of the carbon fiber plate, and give full play to the strength of the three reinforcement materials.

3) The cracking load, structural stiffness and ultimate bearing capacity of the original beam can be greatly improved simultaneously by the composite reinforcement beam of carbon fiber plate-angle steel outsource-external prestress.

4) The increment of cracking load and ultimate load of the composite beam strengthened with carbon fiber plateexternal Angle steel and external prestress is greater than the sum of the increment of the beam strengthened with carbon fiber sticking, external Angle steel and external prestress alone, which is $1+1+1>3$. Reinforcement effect.

\section{References}

1. Cao Fubo, Yin Runping, Wang Chenxia. Flexural performance test of composite reinforced concrete beams $[\mathrm{J}]$. China Journal of Chongqing University, 2017, (07): 9-18.

2. Long Qin, Chu long CE. Application of externally prestressed CFRP in strengthening beam bridges [J]. Chinese foreign highway, 2020, (03): 157-159.

3. Karam E C, Hawileh R A, El M T, et al. Experimental investigations of repair of predamaged steelconcrete composite beams using CFRP laminates and mechanical Structures,2017,112:107-117.

4. Correia L, Teixeira T, Michels J, et al. Flexural behaviour of RC slabs strengthened with prestressed CFRP strips using different anchorage systems[J].Composites Part B:Engineering,2015,81:158-170.

5. Fu Zhiqiang, Liu Guohui, Xiao Chengzhi. Experimental study on strengthening effect of prestressed concrete hollow slab beam with steel plate and CFRP [J]. Journal of Hebei University of water resources and electric power, 2020, (03): 22-27.

6. Macdougall C, Green M, Amato L. CFRP tendons for the repair of post-tensioned, unbonded concrete buildings[J].Journal of Performance of Constructed Facilities,2010,25(3):149-157.

7. Grelle S V, Sneed L H. Review of anchorage systems for externally bonded FRP laminates[J]. International Journal of Concrete Structures and Materials, 2013, 7 (1) :17-33.

8. Shan Cong. Finite element analysis of fire resistance of reinforced concrete beams strengthened with angle steel [J]. Jiangsu architecture, 2017, (04): 19-21.

9. Zhang Yunqing, Zhao Qingyun, Meng Tao. Study on external prestressing reinforcement technology of concrete continuous box girder [J]. Chinese foreign highway, 2020, (03): 164-167.

10. Nie Shuhua, sun Jufeng, Liu fjiang, et al. Crack development and failure analysis of composite strengthened beams [J].China Journal of Shandong Agricultural University, 2010, (01): 129-136. 